\title{
Dysfunction of $\mathrm{Ca}^{2+} / \mathrm{CaM}$ kinase II $\alpha$ cascades in the amygdala in post-traumatic stress disorder
}

\author{
BING XIAO, FANG HAN and YU-XIU SHI
}

\begin{abstract}
Department of Histology and Embryology, Basic Medical Sciences College, China Medical University, Shenyang 110001, Liaoning Province, P.R. China
\end{abstract}

Received July 21, 2009; Accepted September 7, 2009

\author{
DOI: 10.3892/ijmm_00000294
}

\begin{abstract}
Single-prolonged stress (SPS) is an established animal model for post-traumatic stress disorder (PTSD). The calcium $\left(\mathrm{Ca}^{2+}\right)$-calmodulin $(\mathrm{CaM})-\mathrm{CaM}$ kinase $(\mathrm{K}) \mathrm{II} \alpha$ signal passage plays an important role in the plasticity of central nervous, learning and memory, mind and behavior and other types of cognitive activities. The amygdala is known to play an important role in fear, rage and emotional memory. In this study, we investigated changes in $\mathrm{Ca}^{2+}-\mathrm{CaM}-\mathrm{CaMKII} \alpha$ in the basolateral amygdala of rats after SPS which may reveal part of the pathogenesis of PTSD. The intracellular free calcium level in the basolateral amygdala was examined by fluorescence spectrophotometry. CaM and CaMKII $\alpha$ expression in basolateral amygdala was examined using immunohistochemistry, western blotting and reverse transcriptionpolymerase chain reaction. The intracellular free calcium level in the basolateral amygdala was increased when compared to that in the control group 1 day after SPS exposure $(\mathrm{P}<0.05)$. CaM expression significantly increased, and CaMKII $\alpha$ expression significantly decreased $(\mathrm{P}<0.05)$ in the basolateral amygdala after SPS. These findings suggest dysfunction of $\mathrm{Ca}^{2+}-\mathrm{CaM}-\mathrm{CaMKII} \alpha$ in the basolateral amygdala of SPS rats, which may play important roles in the pathogenesis of PTSD rats.
\end{abstract}

\section{Introduction}

Post-traumatic stress disorder (PTSD) is an anxiety disorder that develops after exposure to a life-threatening traumatic experience. It is characterized by symptoms that often endure for years including the continuous re-experience of the traumatic event, avoidance of stimuli associated with the trauma, numbing of general responsiveness, and increased

Correspondence to: Professor Yu-Xiu Shi, Department of Histology and Embryology, Basic Medical Sciences College, China Medical University, 92 North 2nd Road, Shenyang 110001, Liaoning Province, P.R. China

E-mail: shiyuxiu@163.com

Key words: single-prolonged stress, post-traumatic stress disorder, calcium, calmodulin, CaM kinase II $\alpha$, basolateral amygdala arousal (1-3). The pathophysiology of PTSD has been widely studied in neuroscience (4). Several clinical neuroendocrinological studies have significantly improved our understanding of PTSD. One of the core neuroendocrine abnormalities related to the disorder is the dysfunction of the hypothalamo-pituitary-adrenal (HPA) axis, characterized by low levels of adrenocorticotropic hormone (ACTH), plasma cortical and urinary cortisol and enhanced suppression of cortisol in response to low-dose dexamethasone administration $(5,6)$. These neuroendocrine findings specific to PTSD have served as the basis for animal models that are useful for elucidating the pathophysiology of PTSD. Singleprolonged stress (SPS) is a reliable animal model of PTSD based on the time-dependent dysregulation of the HPA axis and has been developed and employed for PTSD research (7-9).

Calcium $\left(\mathrm{Ca}^{2+}\right)$ is an important intracellular second messenger. Elevated $\left[\mathrm{Ca}^{2+}\right]_{i}$ binds to numerous proteins, from low-affinity/high-capacity buffer proteins. The influx of calcium ions results in calmodulin (CaM) activation. Many $\mathrm{Ca}^{2+} / \mathrm{CaM}$ targets modulate cellular signaling pathways. CaM kinase $(\mathrm{K})$ II is a major mediator of calcium signaling and is of particular importance in the brain, playing a key role in the regulation of nerve functions (10).

The amygdala, one of the key regions in the limbic system of the brain, is known to have an important role in fear, rage and emotional memory $(11,12)$. The amygdala modulates memory consolidation with the storage of emotionally relevant information and is critical for the formation of long-term aversive memory, especially for the modulation of anxiety, fear and aggression $(13,14)$. In addition, the amygdala plays a pivotal role in the neural circuitry of stress (15). The amygdala is usually divided into three distinct nuclear subgroups: the central nucleus, corticomedial nucleus and basolateral nucleus (16). Of these nuclear subgroups, the basolateral nucleus is the largest of the amygdala $(17,18)$ and is one of the key regions of fear formation. This study focused on the observation of changes in $\mathrm{Ca}^{2+}-\mathrm{CaM}-\mathrm{CaMKII} \alpha$ in the basolateral amygdala to ascertain how $\mathrm{Ca}^{2+}-\mathrm{CaM}$ CaMKII $\alpha$ cascades participate in PTSD.

\section{Materials and methods}

Experimental animals. Ninety male Wistar rats, weighing 150$180 \mathrm{~g}$, aged 8 weeks at the start of the study, were supplied by 
the Animal Experimental Center, China Medical University. The protocol was carried out in accordance with the Guidance Suggestions for the Care and Use of Laboratory Animals, the Ministry of Science and Technology of the People's Republic of China (19).

Model establishment and grouping. Animals were divided randomly into three groups: i) the control group; ii) SPS 1d (1-day) group; and iii) SPS 7d (7-day) group. Control animals remained in their home cages with no handling for 7 days and were sacrificed at the same time as the SPS groups. SPS rats underwent the SPS procedure on the first day. The SPS protocol was based on a combined plural stress paradigm $(7,20)$ : immobilization (compression with plastic bags) for $2 \mathrm{~h}$, forced swimming for $20 \mathrm{~min}\left(24 \pm 1^{\circ} \mathrm{C}\right)$, rest for $15 \mathrm{~min}$, followed by drying and ether anesthesia (until consciousness was lost).

Perfusion-based sections. Rats of both the normal control and SPS groups were prepared by left ventricle perfusion and fixation (21), and post-fixed in the same fixative at $4^{\circ} \mathrm{C}$ for 6-10 h. They were then immersed in a $20 \%$ sucrose solution in $0.01 \mathrm{M}$ phosphate buffer $(\mathrm{PB}, \mathrm{pH} 7.4)$ at $4^{\circ} \mathrm{C}$. Samples were snap-frozen in liquid nitrogen and sectioned. Coronal sections $(12-\mu \mathrm{m})$ were prepared for the morphological studies.

Determination of free calcium content in basolateral amygdala cells. Rats were rapidly decapitated, and the brains were removed and immediately placed in a dish standing on crushed ice. The basolateral amygdala was then dissected out according to the atlas of rats (22) using a stereomicroscope and snap-frozen in liquid nitrogen and washed twice with cold $200 \mathrm{mM}$ Tris-buffered saline (TBS, pH 7.5). A cell suspension $\left(10^{9}-10^{10} / 1\right)$ was prepared by a routine method and loaded with $1 \mathrm{mmol} / \mathrm{l}$ Fura-2/AM (Beyotime, China) for $35 \mathrm{~min}$, and then detected with a spectrofluorometer (23).

Immunohistochemical analysis of CaM and CaMKIIa. The sections were treated with $5 \%$ bovine serum albumin (BSA), $0.3 \%$ Triton X-100 in PBS for $30 \mathrm{~min}$ at room temperature (RT) to block non-specific staining. The sections were then incubated with mouse monoclonal antibody against CaM (Sigma, USA; 1:100) or CaMKII $\alpha$ (Santa Cruz, USA; 1:200) in $2 \%$ BSA-PBS overnight at $4^{\circ} \mathrm{C}$. After being washed with $\mathrm{PBS}$, the sections were incubated with goat anti-mouse IgG (Boster, China; 1:100) for $2 \mathrm{~h}$ and then with the streptomycin-avidin-biotin-peroxidase complex (SABC) for $1 \mathrm{~h}$. The sections were washed three times with PBS after each incubation and subsequently incubated with 3,3'-diaminobenzidine (DAB) and $\mathrm{H}_{2} \mathrm{O}_{2}$. To assess nonspecific staining, a few sections in every experiment were incubated in buffer without primary antibody.

Five slides were randomly selected from each group. Five visual fields of the basolateral amygdala were randomly selected in each slide (x400). We recorded the optical density (OD) of positive cells in each field to evaluate the average OD. The ODs of immunoreactivity of CaM- and CaMKII $\alpha-$ immunopositive cells were analyzed using the MetaMorph/ DPIO/BX41 morphology image analysis system.
Table I. The primer sequences of $\mathrm{CaM}, \mathrm{CaMKII} \alpha$ and $\beta$-actin.

\begin{tabular}{|c|c|c|c|}
\hline Name & $\begin{array}{l}\text { Upstream } \\
\text { primer }\end{array}$ & $\begin{array}{c}\text { Downstream } \\
\text { primer }\end{array}$ & $\begin{array}{c}\text { Product size } \\
\text { (bp) }\end{array}$ \\
\hline $\mathrm{CaM}$ & $\begin{array}{l}\text { 5'-ggcatcctgett } \\
\text { tagcctgag-3' }\end{array}$ & $\begin{array}{r}5 \text { '-acatgctatccc } \\
\text { tctcgtgtga-3' }\end{array}$ & 328 \\
\hline $\mathrm{CaMKII} \alpha$ & $\begin{array}{c}\text { 5'-catcctcaccac } \\
\text { tatgctg-3' }\end{array}$ & $\begin{array}{c}\text { 5'-atcgatgaaagt } \\
\text { ccaggccg-3' }\end{array}$ & 284 \\
\hline B-actin & $\begin{array}{c}\text { 5'-atcacccacact } \\
\text { gtgcccatc-3' }\end{array}$ & $\begin{array}{r}\text { 5'-acagagtacttg } \\
\text { cgctcagga-3' }\end{array}$ & 542 \\
\hline
\end{tabular}

Western blotting to detect CaM and CaMKIIa. Materials were obtained as above. Samples of normal control rats and SPS rats were respectively homogenized with a sample buffer containing $200 \mathrm{mM}$ TBS, pH 7.5, 4\% SDS, 20\% glycerol, $10 \%$ 2-mercaptoethanol and denatured by boiling for $3 \mathrm{~min}$. The protein fraction ( $30 \mu \mathrm{g} / \mathrm{lane})$ prepared from each sample was separated by $12 \%(\mathrm{w} / \mathrm{v})$ gradient sodium dodecyl sulfate (SDS)-polyacrylamide gel electrophoresis (PAGE) and electroblotted to a PVDF membrane (Millipore, Bedford, MA, USA) from the gel by a semi-dry blotting apparatus (Bio-Rad Laboratories, Inc., Hercules, CA, USA).

The membrane was blocked with $5 \%$ dried skim milk, $0.05 \%$ Tween-20 in TBST at RT for $2 \mathrm{~h}$ and incubated with mouse monoclonal antibody against CaM $(1: 1,000)$ or CaMKII $\alpha(1: 5,000)$ overnight at $4^{\circ} \mathrm{C}$.

Blots were washed three times with TBST, and then incubated with anti-mouse IgG-HRP (Santa Cruz; 1:5000) for $2 \mathrm{~h}$ at RT and washed with TBST. After the incubation, the PVDF membrane was washed three times with TBST before visualization using enhanced chemiluminescence (ECL; Amersham Pharmacia Biotech, Buckinghamshire, UK). To confirm equal protein loading, the same blots were reincubated with antibodies specific for B-actin (Abcam, UK; $1: 1,000)$. Immunoreaction for $B$-actin was detected with ECL. The OD was analyzed on the Gel Image Analysis System. The levels of $\mathrm{CaM}$ and $\mathrm{CaMKII} \alpha$ were determined by calculating the OD ratio of $\mathrm{CaM} / \beta$-actin and CaMKII $\alpha / \beta$-actin.

Reverse transcription-polymerase chain reaction to detect CaM and CaMKIIa. Total mRNA was extracted from the basolateral amygdala using the Trizol Kit according to the manufacturer's instructions. The primers were designed by Shenggong Biotech Co. (Shanghai, China) according to the serial number from Genbank and are shown in Table I. The reaction was started at $94^{\circ} \mathrm{C}$ for 4 min and amplified for CaM for 32 cycles of $30 \mathrm{sec}$ at $94^{\circ} \mathrm{C}, 30 \mathrm{sec}$ at $58^{\circ} \mathrm{C}, 40 \mathrm{sec}$ at $72^{\circ} \mathrm{C}$ and ended with a 7 -min extension at $72^{\circ} \mathrm{C}$. It was started at $95^{\circ} \mathrm{C}$ for $2 \mathrm{~min}$ and amplified for CaMKII $\alpha$ for 33 cycles of $30 \mathrm{sec}$ at $95^{\circ} \mathrm{C}, 30 \mathrm{sec}$ at $55^{\circ} \mathrm{C}, 40 \mathrm{sec}$ at $72^{\circ} \mathrm{C}$ and ended with a 5 -min extension at $95^{\circ} \mathrm{C}$. B-actin mRNA used as an internal control was co-amplified with CaM mRNA and CaMKII $\alpha$. The products were observed after electrophoresis on a $1.2 \%$ agarose gel, and the density of each band was analyzed on the Gel Image Analysis System. The levels of 
CaM mRNA and CaMKII $\alpha$ mRNA were determined by calculating the density ratio of CaM mRNA/B-actin mRNA and CaMKII $\alpha$ mRNA/ß-actin mRNA.

Statistical analysis. All data were expressed as the mean \pm SD. Data among groups were analyzed by one-way analysis of variance (ANOVA) using SPSS 13.0 software. A value of $\mathrm{P}<0.05$ was considered statistically significant.

\section{Results}

Analysis of fluorescence of free calcium content in basolateral amygdala cells. Intracellular free calcium in the basolateral amygdala neurons was notably higher at day 1 after SPS stimulation than that in the control group and gradually reached a normal level at day 7 after SPS (Fig. 1).

Immunohistochemical analysis of CaM and CaMKIIa. CaM and CaMKII $\alpha$ widely distributed throughout the basolateral amygdala region, mainly in the cytoplasm, appeared as buffy particles (Fig. 2A and B). Evaluation of the CaM content by immunohistochemistry indicated a significant increase in the SPS model groups compared with the normal control group; the CaMKII $\alpha$ content was most significantly decreased in the amygdala of the SPS group compared to that in the normal control rats (Fig. 2C).

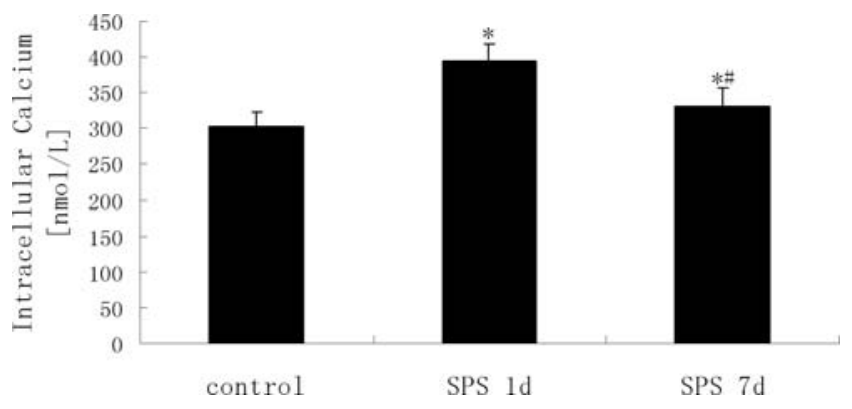

Figure 1. Alterations of intracellular $\mathrm{Ca}^{2+}(\mathrm{nmol} / \mathrm{l})($ mean $\pm \mathrm{SD}) .{ }^{*} \mathrm{P}<0.05$ vs control group, ${ }^{\#} \mathrm{P}<0.05$ vs SPS $1 \mathrm{~d}$ (1-day) group.

Western blotting of CaM and CaMKIIa. Immunoreactive signals for CaM, CaMKII $\alpha$ and $\beta$-actin appeared at 16.7, 50 and $42 \mathrm{kDa}$, respectively (data not shown), and the mean value of band densities of the control group was set as $100 \%$. Data were expressed as normalized optical density. Changes in $\mathrm{CaM}$ and CaMKII $\alpha$ expression in the basolateral amygdala region between the control and SPS groups are presented in Fig. 3. CaM protein expression of the basolateral amygdala showed a significant up-regulation at day 1 after SPS stimulation in comparison with the control rats. In contrast,
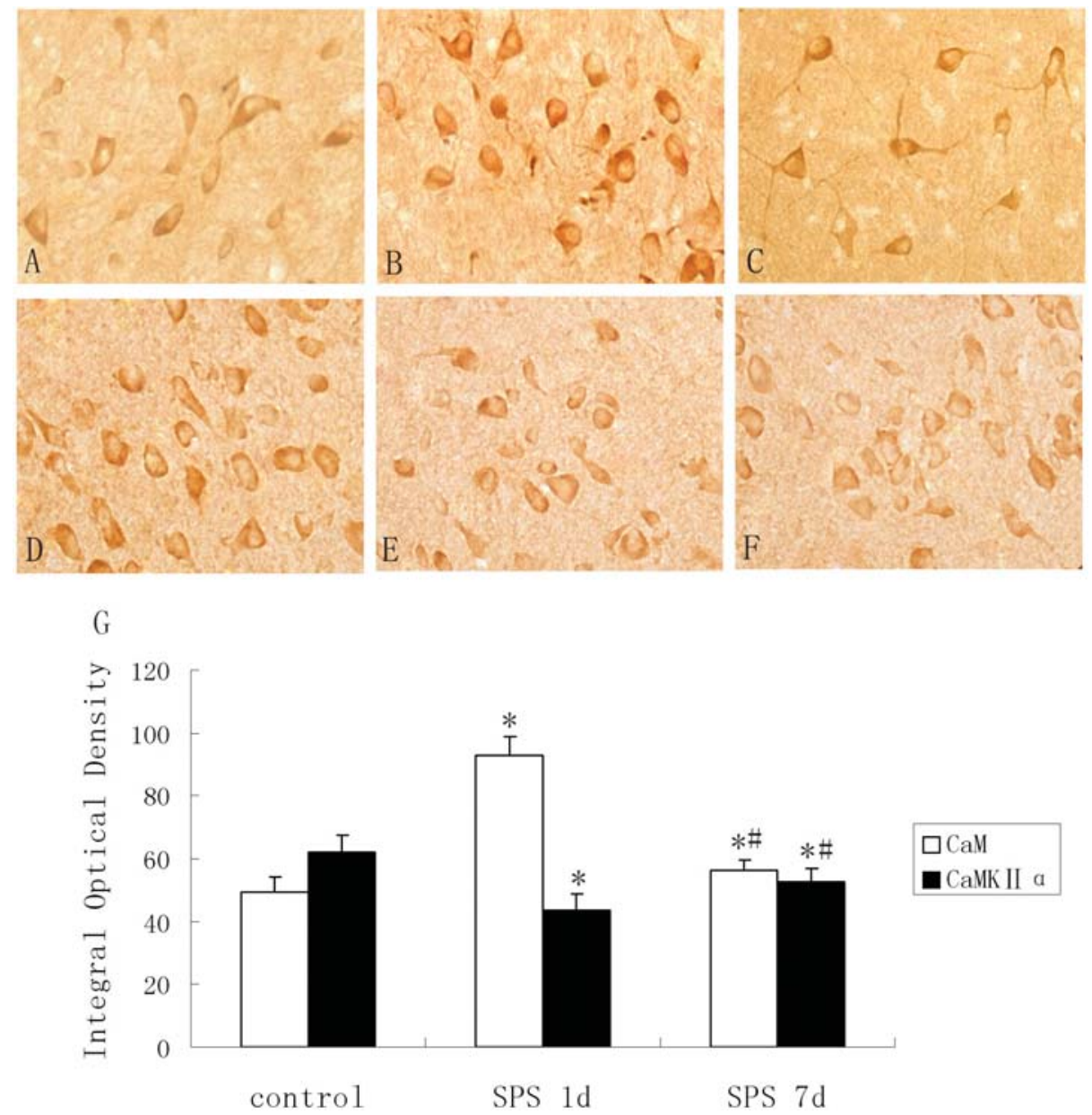

Figure 2. CaM and CaMKII $\alpha$ expression in the basolateral amygdala in each group (A-E, magnification x400). The quantity of CaM-immunoreactive cells in the SPS 1d rats (B) exceeds that of the control (A) and SPS 7d (C) rats. The quantity of CaMKII $\alpha$-immunoreactive cells in the SPS 1d rats (E) was decreased compared with that of the control (D) and SPS 7d (F) rats. Quantitative analysis of the optical density (G). ${ }^{*} \mathrm{P}<0.05$ vs control group, ${ }^{\#} \mathrm{P}<0.05$ vs SPS $1 \mathrm{~d}$ group. 


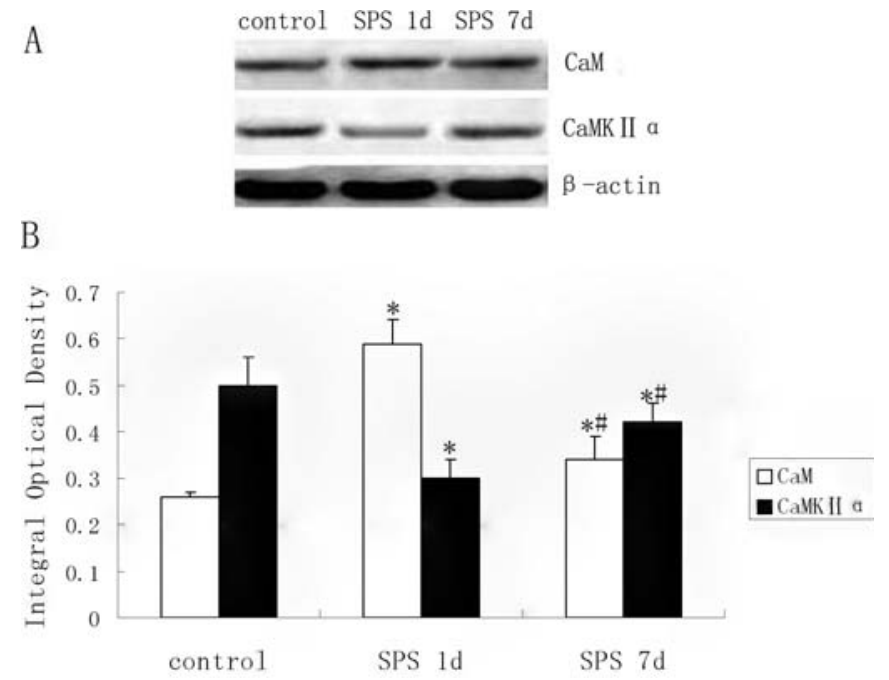

Figure 3. CaM and CaMKII $\alpha$ expression in basolateral amygdala by Western blotting. Bands show CaM and CaMKII $\alpha$ protein levels (A). Relative quantitative levels of $\mathrm{CaM}$ and CaMKII $\alpha$ (B). ${ }^{*} \mathrm{P}<0.05$ vs the control group, ${ }^{\#} \mathrm{P}<0.05$ vs the SPS $1 \mathrm{~d}$ (1-day) group.

the basolateral amygdala CaMKII $\alpha$ expression showed a significant down-regulation throughout.

CaM and CaMKIIa mRNA expression. The levels of CaM mRNA and CaMKII $\alpha$ mRNA were normalized with $\beta$-actin mRNA level. The levels of CaM mRNA increased more significantly in the SPS group than in the control group. In contrast, CaMKII $\alpha$ mRNA expression decreased throughout (Fig. 4).

\section{Discussion}

SPS is one of the animal models proposed for PTSD (20). The SPS rats show enhanced inhibition of the hypothalamopituitary-adrenal (HPA) axis, which has been frequently demonstrated in patients with PTSD.

The special role of the amygdala in the processing of threat-related stimuli, in particular anger and fear, is well documented (14). Abundant evidence from both animal and human investigations strongly suggests that the amygdala, one of the regions in the limbic system of the brain, is responsible for enhancement of explicit memory associated with emotional arousal (24-26). In addition, many lines of evidence have implicated the basolateral amygdala as a substrate for stress-related modulation of memory (27).

Calmodulin $(\mathrm{CaM})$, a ubiquitous calcium sensor protein, is involved in almost all intracellular events. CaMKII is the molecular basis of learning and memory (28), but in the absence of bound calcium/calmodulin, CaM kinase II is in an inactive conformation. The influx of calcium ions results in CaM kinase II activation (29). $\mathrm{Ca}^{2+} / \mathrm{CaM}$ kinase II is a major mediator of calcium signaling and is of particular importance in the brain (30), playing a key role in the regulation of nerve functions, including learning and memory $(31,32)$. CaMKII $\alpha$ and CaMKIIß are thought to have different roles in regulating neuronal functions. It is speculated that CaM kinase II $\alpha$
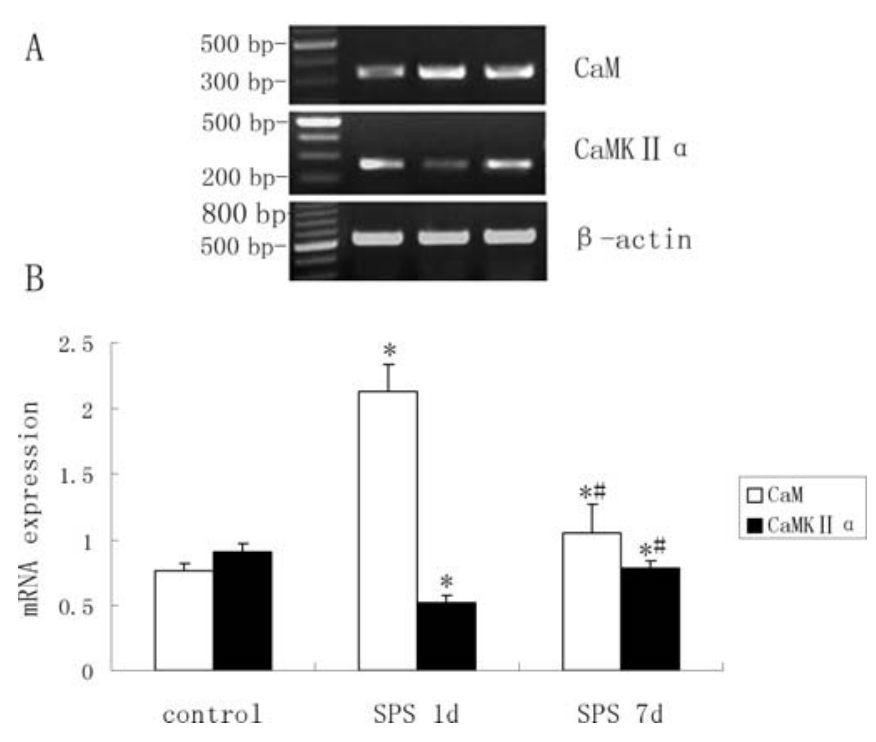

Figure 4. Representative gel pattern of CaM, CaMKII $\alpha$, B-actin cDNA bands (Lane 0, marker; lane 1, control; lane 2, SPS 1d; lane 3, SPS 7d) (A) and relative $\mathrm{CaM}$ and $\mathrm{CaMKII} \alpha$ mRNA expression (B). ${ }^{*} \mathrm{P}<0.05$ as compared to the control group, ${ }^{\#} \mathrm{P}<0.05$ as compared to the SPS $1 \mathrm{~d}$ group.

responds to a strong and/or repeated stimulus in which cellular $\mathrm{Ca}^{2+}$ concentration is relatively high. CaM kinase II $\alpha$ is more effective in synaptic plasticity than CaM kinase IIß, and is thought as one of the best candidates of memory molecule (33).

Evidence that the amygdala is part of a neural mechanism that can modulate a differential susceptibility of multiple memory systems to emotional arousal during acquisition (34), memory consolidation (35) and/or memory retrieval (present study), may provide a novel approach to elucidating the range of mnemonic dysfunction in PTSD.

In this study, detection of free calcium content in the basolateral amygdala neurons revealed calcium overload 1 day after SPS stimulation. Further analysis of $\mathrm{CaM}$, the main calcium conjugated protein in the CNS, showed that expression of total CaM in the basolateral amygdala markedly increased 1 day after SPS stimulation suggesting that the CaM content changed synchronously with changes in the $\mathrm{Ca}^{2+}$ concentration. This occurred because SPS increased the intracellular free calcium level in the basolateral amygdala neurons inducing overexpression of the CaM protein. Changes in CaMKII $\alpha$ from inactive to pCaMKII $\alpha$ lead to decreased content of CaMKII $\alpha$ in the basolateral amygdala after SPS exposure. Due to the important roles of the $\mathrm{Ca}^{2+}-\mathrm{CaM}-\mathrm{CaMKII} \alpha$ signal passage in the plasticity of central nervous, learning and memory, mind and behavior and other types of cognitive activities (36), the dysfunction of $\mathrm{Ca}^{2+}-\mathrm{CaM}-\mathrm{CaMKII} \alpha$ of the basolateral amygdala might be the important pathobiological basis for abnormality of affect and behavior induced by PTSD.

At present, the pathogenesis of PTSD is not yet entirely clear. PTSD may result in a series of biochemical and physiological abnormalities in the brain, which leads to dysfuction of the amygdala. Thus, the pathogenesis of PTSD requires further study. 


\section{Acknowledgements}

The authors thank all of the staff members of the China Medical University Experiment Center for their technical support. In addition, this research was supported by a grant from the National Natural Science Foundation of China (no. 30600341).

\section{References}

1. American Psychiatric Association: Diagnostic and Statistical Manual of Mental Disorders, 4th edition. DSM-IV. American Psychiatric Press, Washington, DC, 1994.

2. Li S, Murakami Y, Wang M, Maeda K and Matsumoto K: The effects of chronic valproate and diazepam in a mouse model of posttraumatic stress disorder. Pharmacol Biochem Behav 85: 324-331, 2006.

3. Siegmund A and Wotjak CT: A mouse model of posttraumatic stress disorder that distinguishes between conditioned and sensitised fear. J Psychiatr Res 41: 848-860, 2007.

4. Kessler RC: Posttraumatic stress disorder: the burden to the individual and to society. J Clin Psychiatry 61: 4-12, 2000.

5. Yehuda R, Golier JA, Halligan SL, Meaney M and Bierer LM The ACTH response to dexamethasone in PTSD. Am J Psychiatry 161: 1397-1403, 2004.

6. de Kloet CS, Vermetten E, Geuze E, Kavelaars A, Heijnen CJ and Westenberg HG: Assessment of HPA-axis function in posttraumatic stress disorder: pharmacological and non-pharmacological challenge tests, a review. J Psychiatr Res 40: 550-567, 2006.

7. Takahashi T, Morinobu S, Iwamoto Y and Yamawaki S: Effect of paroxetine on enhanced contextual fear induced by single prolonged stress in rats. Psychopharmacology 189: 165-173, 2006.

8. Iwamoto Y, Morinobu S, Takahashi T and Yamawaki S: Single prolonged stress increases contextual freezing and the expression of glycine transporter 1 and vesicle-associated membrane protein $2 \mathrm{mRNA}$ in the hippocampus of rats. Prog Neuropsychopharmacol Biol Psychiatry 31: 642-651, 2007.

9. Khan S and Liberzon I: Topiramate attenuates exaggerated acoustic startle in an animal model of PTSD. Psychopharmacology 172: 225-229, 2004.

10. Sanhueza M, Mcintyre CC and Lisman JE: Reversal of synaptic memory by $\mathrm{Ca}^{2+} /$ calmodulin-dependent protein kinase I inhibitor. J Neurosci 27: 5190-5199, 2007.

11. McGaugh JL and Cahill L: Interaction of neuromodulatory systems in modulating memory storage. Behav Brain Res 83 31-38, 1997.

12. LeDoux JE: Emotion: clues from the brain. Annu Rev Psychol 46: 209-235, 1995.

13. Cui H, Sakamoto H, Higashi S and Kawata M: Effects of singleprolonged stress on neurons and their afferent inputs in the amygdala. Neuroscience 152: 703-712, 2008.

14. Derntl B, Windischberger C, Robinson S, Kryspin-Exner I, Gur RC, Moser E and Habel U: Amygdala activity to fear and anger in healthy young males is associated with testosterone. Psychoneuroendocrinology 34: 687-693, 2009.

15. Shekhar A, Truitt W, Rainnie D and Sajdyk T: Role of stress, corticotrophin releasing factor (CRF) and amygdala plasticity in chronic anxiety. Stress 8: 209-219, 2005.

16. Harding AJ, Stimson E, Henderson JM and Halliday GM: Clinical correlates of selective pathology in the amygdala of patients with Parkinson's disease. Brain 125: 2431-2445, 2002.

17. Sims KS and Williams RS: The human amygdaloid complex: a cytologic and histochemical atlas using Nissl, myelin, acetylcholinesterase and nicotinamide adenine dinucleotide phosphate diaphorase staining. Neuroscience 36: 449-472, 1990.
18. Gloor P: The amygdaloid system. In: The Temporal Lobe and Limbic System. Oxford University Press, New York, pp591-721, 1997.

19. The Ministry of Science and Technology of the People's Republic of China. Guidance Suggestions for the Care and Use of Laboratory Animals, 2006.

20. Kohda K, Harada K, Kato K, Hoshino A, Motohashi J, Yamaji T, Morinobu S, Matsuoka N and Kato N: Glucocorticoid receptor activation is involved in producing abnormal phenotypes of single-prolonged stress rats: a putative post-traumatic stress disorder model. Neuroscience 148: 22-33, 2007.

21. Liu HY: Technical operations and its common problems of perfusion fixation in mice. Qiqihaer Yixueyuan Xuebao 27: $1341,2006$.

22. Paxinos G and Watson C: The Rat Brain in Stereotaxic Coordinates. 4th edition, Academic Press, 1998.

23. Liqiong L, Peiqiang $\mathrm{H}$ and Qingzhi K: Effects of polysaccharides on intracellular free calcium concentration of sarcoma S-180 cells. Tumor 28: 236-237, 2008.

24. McGaugh JL: The amygdala modulates the consolidation of memories of emotionally arousing expriences. Annu Rev Neurosci 27: 1-28, 2004.

25. Cahill L and McGaugh JL: Mechanisms of emotional arousal and lasting declarative memory. Trends Neurosci 21: 294-299, 1998.

26. Hamann S: Cognitive and neural mechanisms of emotional memory. Trends Cogn Sci 5: 394-400, 2001.

27. Chavez CM, McGaugh JL and Weinberger NM: The basolateral amygdala modulates specific sensory memory representations in the cerebral cortex. Neurobiol Learn Mem 91: 382-392, 2009.

28. Chen HX, Otmakhov N, Strack S, Cilbran RJ and Lisman JE: Is persistent activity of calcium/calmodulin-dependent kinase required for the maintenance of LTP? J Neurophysiol 85: 1368-1376, 2001.

29. Tan SE: Activation of hippocampal nitric oxide and calcium/ calmodulin-dependent protein kinase II in response to Morris water maze learning in rats. Pharmacol Biochem Behav 92: 260-266, 2009

30. Goldenring JR, Gonzalez B, McGuire JS Jr and Delorenzo RJ: Purification and characterization of a calmodulin-dependent kinase from rat brain cytosol able to phosphorylate tubulin and microtubule-associated proteins. J Biol Chem 258: 12632-12640, 1983.

31. Lisman J, Schulman $\mathrm{H}$ and Cline $\mathrm{H}$ : The molecular basis of CaMKII function in synaptic and behavioural memory. Nat Rev Neurosci 3: 175-190, 2002.

32. Yamauchi T: Neuronal $\mathrm{Ca}^{2+} /$ calmodulin-dependent protein kinase II-discovery, progress in a quarter of a century, and perspective: implication for learning and memory. Biol Pharm Bull 28: 1342-1354, 2005.

33. Deguchi A, Hata M, Uhara T and Yamauchi T: Domain structure responsible for the different properties between alpha and beta $\mathrm{Ca}^{2+} /$ calmodulin-dependent protein kinase II analyzed by their chimera enzymes. Brain Res 1238: 1-11, 2008.

34. Packard MG and Wingard JC: Amygdala and 'emotional' modulation of the relative use of multiple memory systems. Neurobiol Learn Mem 82: 243-252, 2004.

35. Wingard JC and Packard MG: The amygdala and emotional modulation of competition between cognitive and habit memory. Behav Brain Res 193: 126-131, 2008.

36. Wang WD, Cheng YH and Wang JC: Dentate granule cell neurogenesis after diffuse brain injury in the adult rat. Chin J Clin Rehabil 6: 2864-2865, 2002. 